\title{
Meningkatkan Ketahanan Duduk Saat Proses Pembelajaran Melalui Pemberian Reward Kepada Siswa Autisme
}

\author{
${ }^{1}$ Yolanda Ismudar, ${ }^{2}$ Damri.Damri \\ ${ }^{12}$ Jurusan Pendidikan Luar Biasa, Fakultas Ilmu Pendidikan,Universitas Negeri Padang. \\ Email : yolandaismudar98@gmail.com.
}

\begin{abstract}
This study discusses the analysis of rewording in the form of stickers with star images, in increasing the duration of sitting endurance for autistic students during the learning process. This study used an experimental method with a single subject research approach. The subject of this study was a class VI autistic student who had a low duration of sitting resistance during the learning process in the classroom. Researchers made observations during seventeen meetings, all data were obtained through observation, interviews and action tests which were presented in graphic form. To measure the duration of sitting endurance, the researcher used a stopwarch analysis tool. Overall the results of the research on the initial conditions for five meetings were 2 minutes, 2 minutes, 4 minutes, 3 minutes 3 minutes. Furthermore, in the intervention condition during the seven meetings the researcher gave reword in the form of a star sticker image, the results were 4 minutes, 3 minutes, 4 minutes, 6 minutes, 5 minutes, 7 minutes, 8 minutes. At baseline A2 conditions obtained dudu resistance results After being given the treatment, namely 5 minutes, 5 minutes, 6 minutes, 7 minutes, 9 minutes. The results of this study prove that giving rewords in the form of star stickers in the learning process can increase the duration of sitting endurance for autistic students, but it is necessary to develop further research in this problem in different contexts and issues.
\end{abstract}

Keywords: Reward, Autism Students, Duration Of Sitting Endurance.

\section{Pendahuluan}

Pembelajaran merupakan proses yang dilakukan dilingkungan belajar tertentu sehingga diharapkan terjadi perubahan tingkah laku. Menurut Husni (2018) Metode dalam pembelajaran bersifat fleksibel dan bermacam-macam dapat menyesuaikan hasil dan kondisi pembelajaran yang dicapai untuk mencapai hasil pembelajaran terutama pada saat proses pembelajaran. ${ }^{1}$

Novianti (2011) ${ }^{2}$ proses pembelajaran seorang guru yang baik ialah mampu menciptakan kondisi yang dapat menimbulkan kesenangan,kefokusan serta antusias saat belajar .sehingga siswa mengalami perubahan yang positif. Dengan tuntutan tersebut diharapkan siswa mampu berprilaku positif seperti, duduk tenang, tidak berjalan-jalan, tidak mondar mandir membuang ludah kejendela. Semua prilaku diatas harus diupayakan oleh guru agar proses pembelajaran terlaksana dengan lancar dan tenang. sikap positif yang diberikan guru kepada siswa dengan cara memuji hasil kerja siswa, memberikan tepuk tangan kepada siswa, memberikan hadiah sebagai Penguatan positif. Perilaku tersebut dapat membantu siswa dalam merubah sikap siswa saat proses pembelajaran berlangsung seperti pada prilaku dalam ketahanan duduknya. Ketahanan Islam. 05.

${ }^{1}$ Husni, M. (2018). Analisis Kompreratif dan Sintesa Teori Belajar Konvensional Dengan Teori Belajar Dalam

${ }^{2}$ Novianti, N. R. (2011). Kontribusi pengelolaan laboratorium dan motivasi belajar siswa terhadap efektivitas proses pembelajaran. Jurnal Pendidikan MIPA. Edisi Khusus, 1, 158-166. 
duduk merupakan kemampuan siswa untuk dapat bertahan duduk selama proses pebelajaran.Bagi siswa kebutuhan khusus, ada beberapa siswa yang memiliki masalah dalam ketahanan duduknya. salah satunya yaitu pada siswa autis.

Berdasarkan studi pendahuluan yang dilakukan di SLBN 1 padang ditemukan satu orang siswa autis laki-laki yang duduk dikelas enam semester dua. Siswa ini memiliki kondisi fisik yang normal, berat badan $52 \mathrm{~kg}$, tinggi $158 \mathrm{~cm}$ dan tidak memiliki riwayat penyakit. Ketika sedang duduk belajar dalam kelas siswa ini sering menunjukkan prilaku gelisah dan takbertahan duduk, mengangkat kaki keatas meja, membuang ludah kejendela, menutup mata serta menggelengkan kepala, berjalan mondar mandir, menggoyang-goyangkan meja, tidur dilantai, berjalan dalam kelas, mengeluarkan suara keras dan berdiri melihat orang dijendela.

Perilaku-perilaku yang muncul diatas menunjukkan bahwa anak ini tidak bisa tenang dan tak mampu bertahan duduk. Hal tersebut membuat guru kewalahan mengajar siswa padahal guru sudah mencoba berbagai cara agar siswa mampu duduk tenang dibangkunya seperti belajar sambil bernyanyi tetapi tetap saja siswa tidak dapat tenang duduk dibangkunya saat proses pembelajaran berlangsung.

Berdasarkan hasil pengamatan peneliti disaat pembelajaran berlangsung sebanyak 5 kali, pada pertemuan I guru menginstruksikan siswa untuk membaca teks cerita yang ada pada bukunya, dalam kegiatan ini siswa memiiki durasi ketahanan duduk selama 2 menit. Pertemuan II pada pembelajaran mengenal bentuk bangun datar siswa diminta untuk menuliskan bentuk bangun datar yang ada dipapan tulis kedalam buku tulisnya, dalam kegiatan ini siswa memiliki durasi ketahanan duduk selama 2 menit.

Pertemuan III pada pembelajaran mengenal nilai mata uang, guru menggunakan metode ceramah dan memperlihatkan uang mainan, dalam kegiatan ini siswa memiliki durasi ketahanan duduk selama 4 menit. Pertemuan IV pada pembelajaran mengenal warna dan bermain plastisin, siswa diminta untuk membuat suatu bentuk dari plestisin pada kegiatan ini siswa memiliki durasi ketahanan duduk selama 3 menit. Pertemuan V pada pembelajaran menyalin teks siswa memiliki durasi ketahanan duduk selama 3 menit.

Selanjutnya penulis mewawancarai guru terkait dengan kondisi diatas dimana guru mengakui kondisi siswa memang seperti yang penulis lihat, guru juga menjelaskan bahwa siswa mengalami ketahanan duduk yang kurang dari 10 menit. Guru sudah berusaha salah satunya memberikan pembelajaran yang disukai siswa seperti membuat bentuk benda dari plastisin, menyusun puzzle. Kendala guru dalam menangani siswa ini berhubung guru belum pernah sebelumnya menangani siswa autis maka guru merasa kewalahan dalam menghadapi sikap siswa yang tidak dapat bertahan duduk dibangkunya.

Berdasarkan hasil studi pendahuluan diatas (hasil observasi, wawancara dan asesmen dalam bentuk tes perbuatan) hasilnya siswa $\mathrm{X}$ mengalami ketahanan duduk yang kurang dari 10 menit terlihat pada hasil asesmen yang telah dijelaskan diatas. Maka dari itu dilihat dari permasalahan-permasalahan diatas penulis tertarik untuk meningkatkan kemampuan ketahanan duduk menggunaan metode ABA. Metode ABA menurut Nurhastuti (2018) merupakan salah satu metode yang syarat dengan konsep 
modifikasi perilaku. ${ }^{3}$ Untuk itu, modifikasi perilaku dapat diterapkan sebagai salah satu pendekatan pembelajaran dalam mengubah perilaku anak autis. Berkaitan dengan itu perilaku menurut Damri (2016) merupakan respon atau perbuatan seseorang, seperti memberikan reword berup stiker bintang penulis mengharapkan siswa mampu fokus, tenang saat belajar, tidak gelisah saat duduk,tidak suka kabur saat jam pembelajaran berlangsung. ${ }^{4}$

Berdasarkan fakta dan data diatas dijelaskan bahwa siswa autis SLBN 1 padang mengalami ketahanan duduk yang kurang dari 10 menit. Prilaku anak tidak bisa duduk dengan tenang ini semata-mata bukanlah kesalahan siswa, tetapi keterbatasan guru mengajar seperti dengan menggunakan metode ceramah dan media yang digunakan guru kurang menarik dan kurangnya pemahaman orang tua dalam memberikan permainan untuk anaknya agar anaknya mampu duduk tenang. Padahal hal ini masih bisa ditingkatkan. Inilah yang mendorong penulis untuk membantu kesulitan yang dialami siswa serta mencarikan alternatif sehingga siswa dapat bertahan duduk dengan tenang selama proses kegiatan pembelajaran berlangsung. Penulis secara langsung menerapkan pemberian reword sebagai alat atau media dalam meningkatkan ketahanan duduk siswa dengan menggunakan eksperimen dengan metode SSR (Single Subject Research).

\section{METODE}

Penelitian ini menggunakan metode Eksperimen dengan pendekatan Single Subjek Research dengan desain A-B-A. Single Subjek Research mengarah ke strategi penelitian yaitu dikembangkan untuk mendokumentasikan perubahan dapat diakibatkan secara sengaja dan sistematis. Maka penelitian ini menggunakan design A-B-A.

Design A-B-A terdiri dari A1, adalah fase baseline yaitu kondisi atau kedaaan natural anak sebelum diberikan intervensi (perlakuan) dan B adalah kondisi atau keadaan intervensi (perlakuan) dan A2 adalah kondisi atau kedaaan setelah di diberi intervensi, yang akan dilihat yaitu kemampuan awal anak sebelum diberikan intervensi dan kemmapuan akhir setelah diberi intervensi kemdian kemampuan setelah tidak diberi intervensi. ${ }^{5}$

Subjek penelitian adalah anak autis (B) dengan inisial X, anak bersekolah di SLBN 1 padang, dengan jenis kelamin laki-laki. Secara fisik anak sama dengan siswa normal pada umumnya. Dari studi pendahuluan yang dilakukan peneliti terlihat pada saat belajar anak tidak bisa duduk dengan tenang,mondar mandir membuang ludah kejendela, berjalan didalam kelas, menggoyang-goyangkan anggota tubuh, menutup mata sambil menggelengkan kepala.

1. Teknik pengumpulan data

${ }^{3}$ Nurhastuti, mega iswari dan. (2018). pendidikan anak autisme. kuningan: goresan pena.

${ }^{4}$ Damri, D. (2017). Suppressing the Hyperactivity Behaviour of Students with Autism Through A Time-Out Strategy. International Conference of Early Childhood Education (ICECE 2017). Atlantis Press.

${ }^{5}$ Damri. (2016). Mengurangi Perilaku Hiperaktivitas Melalui Prosedur Penyisiban Sesaat (Time Out) bagi Anak Autisme”. padang: Universitas Negeri Padang. 
Dalam menghimpun data penelitian menggunakan observasi, penghimpun data dilakukan dengan cara mencatat durasi ketahanan duduk berapa lama siswa dapat bertahan duduk selama proses pembelajaran berlangsung.

2. Alat pengumpulan data

Data dikumpulkan langsung oleh peneliti sebelum dan sesudah anak diberikan treatment. Jenis pencatatan data yang dipilih yaitu pencatatan durasi dengan menghitung berapa durasi anak bisa bertahan duduk selama proses pembelajaran. Alat pengumpulan data dalam penelitian ini adalah menggunakan format pengumpulan data pada kondisi baseline dan pada kondisi treatement dengan menggunakan alat pengukur waktu. Yaitu stopwach, dengan cara pengoperasionalnya sebagai berikut :

a. Menyediakan stopwatch untuk mengukur durasi ketahanan duduk anak.

b. Memastikan stopwatch dalam keadaan nol.

c. Untuk memulai pengukuran waktu menekan tombol star.

d. Untuk mengakhiri pengukuran waktu menekan tombol stop.

e. kemudian tekan tombol star lagi untuk melakukan pengukuran kembali dan stop untuk mengakhiri begitu seterusnya.

Pengumpulan data dilakukan melalui beberapa tahap yaitu (1) peneliti mengamati siswa dan mewawancarai guru (2) peneliti memberikan perlakuan dengan pemberian reword berupa stiker bergambar bintang (3) peneliti mengamati durasi ketahanan duduk siswa tanpa memberikan perlakuan.

\section{Hasil dan Pembahasan}

Dalam penelitian ini peneliti meningkatkan ketahanan duduk anak autis melalui permberian reword berupa gambar stiker bintang. Stiker bintang adalah stiker yang menjadi alat untuk membantu proses pembelajaran berbentuk bintang dengan gambar yang lucu dan digunakan sebagai penguatan positif. Hal yang terpenting dalam ketahanan duduk yaitu adanya media yang dapat terciptanya lamanya ketahanan duduk pada anak autis.

Pengamatan dilakukan dalam tiga kondisi yaitu kondisi Baseline A1 sebelum diberikan perlakuan dengan mengamati berapa lama ketahanan duduk anak pada saat proses pembelajaran, Intervensi (B) setelah diberikan perlakuan pada anak melalui pemberian Riword Berupa Gambar Stiker Bintang dan Baseline A2 mengamati kembali berapa lama ketahanan duduk anak autis pada saat pembelajaran berlangsung.

Pengamatan pada kondisi Baseline (A1) dilakukan sebanyak 5 kali pengamatan dengan hasil 2, 2, 4, 3, dan 3. Pada kondisi Intervensi (B) pengamatan dilakukan sebanyak 7 kali dengan hasil 4, 3, 4, 6, 5, 7, dan 8 sedangkan pada kondisi Baseline (A2) pengamatan dilakukan sebanyak 5 kali dengan hasil diperoleh 5, 5, 6, 7 dan 9 .

Berdasarkan analisis data yang dilakukan dapat dijelaskan bahwa setelah diberikan perlakuan berupa pemberian reword yang bergambar stiker bintang ketahanan duduk anak autis dalam proses pembelajaran mengalami peningkatan. Sehingga intervensi pemberian reward bergambar stiker bintang berpengaruh dalam meningkatkan ketahanan duduk siswa autis kelas VI di SLBN 1 Padang

Gambar 1. 
Grafik rekapitulasi meningkatkan ketahanan duduk siswa autisme melalui pemberian reward berupa stiker bergambar bintang Dalam Kondisi Baseline (A1), Intervensi, Dan Baseline (A2)

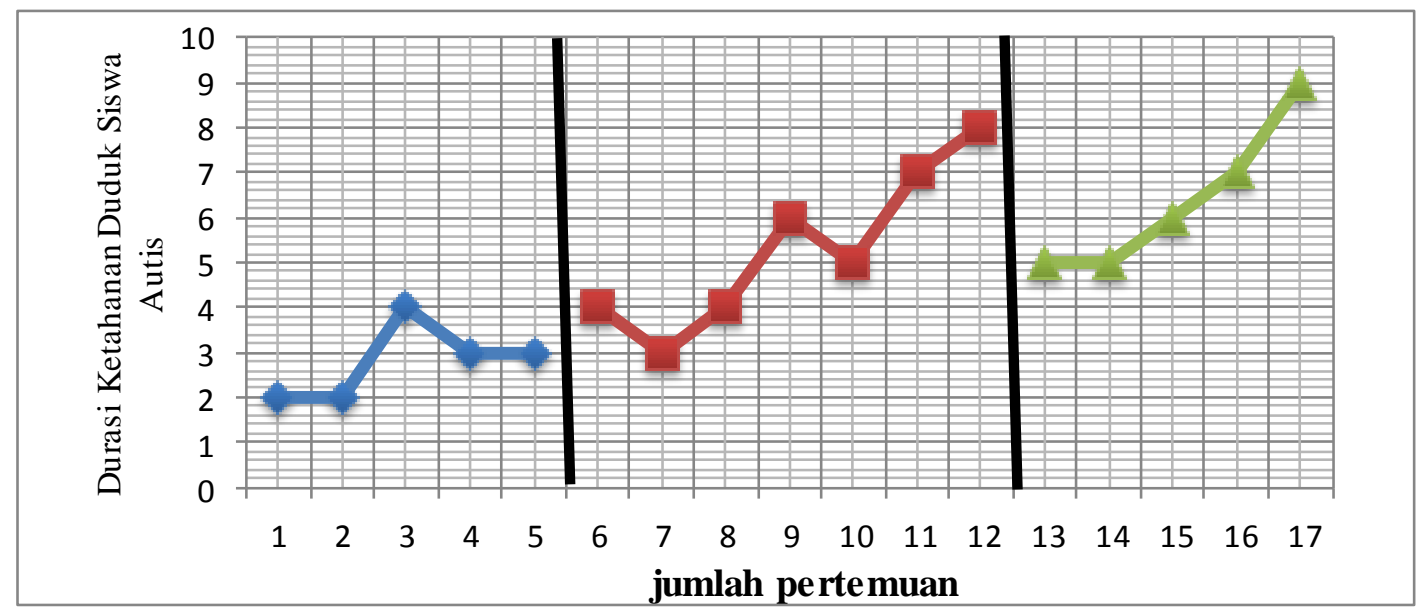

\section{Keterangan :}

Baseline A1:

Intervensi :

Baseline A2 :

1. Analisis data

Hasil analisis data dapat dilihat pada tabel 1 berikut.

Tabel 1.

Rangkuman Hasil Analisis Dalam Kondisi durasi ketahanan duduk siswa melalui pemberian reward stiker bergambar bintang Pada Siswa autisme.

\begin{tabular}{|c|c|c|c|c|}
\hline No & Kondisi & A1 & B & A2 \\
\hline 1 & Panjang kondisi & 5 & 7 & 5 \\
\hline 2 & $\begin{array}{l}\text { Estimasi } \\
\text { kecendrungan arah }\end{array}$ & $(+)$ & $(+)$ & $(+)$ \\
\hline 3 & $\begin{array}{l}\text { Kecendrungan } \\
\text { stabilitas }\end{array}$ & $\begin{array}{l}40 \% \\
\text { Variabel }\end{array}$ & $\begin{array}{l}71,42 \% \\
\text { Variabel }\end{array}$ & $\begin{array}{l}80 \% \\
\text { Stabil }\end{array}$ \\
\hline 4 & Jejak data & $(+)$ & $(+)$ & $(+)$ \\
\hline 5 & $\begin{array}{l}\text { Level stabilitas dan } \\
\text { rentang }\end{array}$ & $\begin{array}{l}\text { Variabel } \\
2-4\end{array}$ & $\begin{array}{l}\text { Variabel } \\
3-8\end{array}$ & $\begin{array}{l}\text { Stabil } \\
5-9\end{array}$ \\
\hline 6 & Level perubahan & $\begin{array}{l}4-2=2 \\
(+)\end{array}$ & $\begin{array}{l}8-3=5 \\
(+)\end{array}$ & $\begin{array}{l}9-5 \\
(+)\end{array}$ \\
\hline
\end{tabular}

Hasil pada analisis data menunjukkan Bahwa pada kondisi Baseline AI yang dilakukan selama lima kali pertemuan yaitu memiliki kecendrungan stabilitas sebesar $40 \%$ dalam rentang $2-4$, rentang tersebut diperoleh dari hasil durasi ketahanan duduk yang terendah hingga yang tertinggi. Selanjutnya pada kondisi intervensi saat diberikan perlakuan berupa reword yang dilaksanakan selama tujuh kali pertemuan yaitu memiliki kecendrungan stabilitas $71,42 \%$ dalam rentang 3-8, rentang tersebut diperoleh dari hasil durasi ketahanan duduk yang terendah hingga yang tertinggi. Kondisi terakhir yaitu Baseline A2 yang dilakukan selama lima kali pertemuan tanpa 
diberikan perlakuan atau reword yaitu memiliki kecendrungan stabilitas sebesar $80 \%$ dalam rentang 5-9, rentang tersebut diperoleh dari hasil durasi ketahanan duduk yang terendah hingga yang tertinggi.

Siswa autis merupakan siswa yang sulit untuk mengelola ketahanan duduknya dengan berbagai gangguan terutama gangguan pada prilaku Berkaitan dengan itu prilaku merupakan respon atau perbuatan seseorang, seperti memberikan reword berup stiker bintang penulis mengharapkan siswa mampu fokus, tenang saat belajar, tidak gelisah saat duduk,tidak suka kabur saat jam pembelajaran berlangsung sedangkan menurut (Irdamurni, 2018) autis ialah gangguan perkembangan neurologis yang meliputi gangguan interaksi sosial, komunikasi, prilaku, emosi serta bahasa dan gejalannya dapat muncul sebelum usia 3 tahun. maka dapat dimaknai autis adalah suatu gangguan perkembangan yang sangat komplek ditandai dengan gangguan prilaku,bahasa, emosi, komunikasi, sosial yang diketahui sebelum anak berumur tiga tahun. ${ }^{6}$ Indamurni juga menjelaskan karakteristik anak autis :

a. Prilaku

Anak autis akan tidak peduli dengan lingkungan, prilaku tak terarah : mondar mandir, berputar-putar, tantrum, obsesive, terpukau terhadap benda yang bergerak atau menarik

b. Interaksi sosial

Kontak mata tidak ada, tidak menoleh ketika dipanggil, asik dengan dirinya sendiri tidak berempati dilingkungan sosial.

Tidak mau menatap, dipanggil tidak menoleh, tak mau bermain dengan teman sebaya, asyik dengan dirinya sendiri, tidak ada empati dalam lingkungan sosial.

Maka dapat dijelaskan karakteristik anak autis adalah suka mengoceh tidak jelas tanpa arti, berkomunikasi menggunakan kata yang berulang-ulang, sulit berkomunikasi dua arah, sulit berinterasksi dengan lingkungan sekitar, memiliki ketertarikan pada benda tertentu, gangguan emosi, memiliki masalah dalam bahasa serta memiliki prilaku tidak tenang suka mondar mandir dan tidak tahan duduk dengan tenang.

Ketahanan duduk merupakan kemampuan siswa untuk dapat bertahan duduk selama proses pebelajaran seperti yang diungkapkan oleh Sari ${ }^{7}$ ketahanan duduk merupakan suatu keadaan atau sikap dimana siswa dapat duduk dengan baik dan tenang serta memiliki konsentrasi tetap selama frekuensi-frekuensi tertentu sesuai dengan usia sekolah anak. (Tarmansyah, 2010) ketahanan duduk anak sesuai dengan usia dan jenajang kelasnya pada anak TK durasi ketahanan duduknya 25-30 menit, SD klelas 1-3 durasi ketahanan duduknya 30-35 menit dan SD kelas 4-6 memiliki durasi ketahanan duduk 40-45 menit. Semua prilaku diatas harus

${ }^{6}$ Damri. (2016). Mengurangi Perilaku Hiperaktivitas Melalui Prosedur Penyisiban Sesaat (Time Out) bagi Anak Autisme". padang: Universitas Negeri Padang.

${ }^{7}$ Suci Wulandari, I. K. A. (2014). Pengaruh Pemberian Reward and Punishment Terhadap Motivasi Belajar Siswa dalam Pembelajaran Passing Bawah Bolavoli (Studi pada Siswa Kelas VIII SMP Negeri 1 Yosowilangun Lumajang). Jurnal Pendidikan Olahraga Dan Kesehatan, 2(3). 
diupayakan oleh guru agar proses pembelajaran terlaksana dengan lancar dan tenang guru harus memberikan sikap yang positif dengan cara, guru memuji hasil kerja siswa. Guru memberikan tepuk tangan kepada siswa, memberikan hadiah kepada siswa berupa mainan, permen, stiker bintang atau yang tepat disebut reward.

Reward merupakan penghargaan,imbalan atau hadiah yang diberikan karena telah meaksanakan pembelajaran dengan tepat. Seperti yang dinyatakan oleh (Pettasolong, 2017) reward adalah penghargaan dengan tujuan menyenangkan perasaan peserta didik karena mendapat hasil yang baik dan terpuji. Contoh seorang guru memberikan reward berupa stiker bintang. Stiker bintang merupakan suatu media yang dapat digunakan oleh guru sebagai reword memotivasi siswa dalam proses pembelajaran. ${ }^{8}$

Reward dapat dibedakan menjadi beberapa macam sesuai yang diharapkan oleh peserta didik menurut (Faidy \& Arsana, 2014) Reward dapat dibedakan menjadi tiga macam, yaitu (1) Pemberian nilai atau angka. Angka sebagai simbol kegiatan belajar, angka yang dimaksud adalah bonus nilai/tambahan nilai bagi siswa yang mengerjakan tugas dengan baik. (2) Pemberian pujian seperti dalam pemberian tepuk tangan, pujian sehingga membuat siswa merasa senang dan terpuji.(3) Pemberian hadiah. Berbentuk alat-alat yang disenangi siswa seperti, makanan, alat keperluan sekolah, stiker.

Menurut (Munawaroh, 2019) Stiker bintang adalah stiker yang menjadi alat untuk membantu proses pembelajaran berbentuk bintang dengan gambar yang lucu dan dan menarik sehingga digunakan sebagai penguatan positif. Penguatan positif yang dimaksud yaitu untuk membantu siswa dalam merubah prilaku saat proses pembelajaran berlangsung seperti pada prilaku dalam ketahanan duduknya. Ketahanan duduk merupakan kemampuan siswa untuk dapat bertahan duduk dengan tenang selama frukuensi tertentu pada saat proses pebelajaran berlangsung. ${ }^{9}$

Pemilihan stiker bintang ini didasarkan karena siswa senang sekali mengumpulkan stiker yang bergambar bintang dan menempelkan stiker tersebut dikertas pembelajarannya karena stiker bintang tersebut dapat menarik perhatian siswa serta tampak menarik, dan memiliki warna warni, atas pertimbangan bahwa anak senang pada reward yang menarik seperti stiker bintang dan belum ada pemberian reward berupa stiker bintang. Maka peneliti memberikan reword berupa pemberian stiker bintang pada penelitian ini.

Hasil penelitian ini dengan jelas menunjukkan bahwa pemberian reword berupa stiker bergambar bintang dapat merubah prilaku siswa kearah yang positif saat proses pembelajaran. Hasil penelitian ini didukung oleh penelitian (Suci Wulandari, 2014) (Muqoyyaroh, 2018) Menemukan bahwa dalam pemberian reword berupa stiker bergambar bintang dapat meningkatkan proses pembelajaran pada peserta didik.

\footnotetext{
${ }^{8}$ Pettasolong, N. (2017). Implementasi Budaya Kompetisi Melalui Pemberian Reward And Punishment Dalam Pembelajaran. Tadbir: Jurnal Manajemen Pendidikan Islam, 5(2), 38-52.

${ }^{9}$ Munawaroh, Z. A. (2019). Pengaruh Pemberian Reward Stiker Bintang Terhadap Percaya Diri Anak Kelompok B di TK Thoriqussalam Sidoarjo. Jurnal JECED (Journal of Early Childhood Education and Development), 1(1), 21-29.
} 


\section{Catatan Akhir}

Dapat disimpulkan bahwa durasi ketahanan duduk siswa saat proses pembelajaran meningkat. Sehingga dapat disimpulkan bahwa melalui pemberian reword berupa stiker bergambar bintang dapat meningkatkan durasi ketahanan duduk pada siswa autis kelas VI di SLBN 1 Padang. Hal ini dapat dibuktikan melalui grafik dan teknik analisis data dalam kondisi dan antar kondisi yang didapatkan melalui durasi satuan menit selama proses pembelajaran berlangsung. Berdasarkan hasil penelitian ini peneliti berharap kepada semua pihak yang terkait dalam pendidikan berkebutuhan khusus, salah satunya siswa autisme untuk dapat memberikan pendidikan yang sesuai dengan kebutuhan dan kondisi siswa terutama kepada :

1. Guru dan orang tua. Dalam melatih ketahanan duduk siswa terutama saat proses pembelajaran disarankan kepada guru dan orang tua untuk memberikan reword yang disenangi siswa seperti pemberian stiker kepada siswa karena dapat meningkatkan durasi ketahanan duduk siswa saat proses pembelajaran berlangsung.

2. Sekolah. Bagi sekolah diharapkan agar mendukung pemberian reword kepada siswa salah satunya yaitu seperti pemberian stiker untuk meningkatkan durasi ketahanan duduk siswa saat proses pembelajaran.

3. Bagi peneliti selanjutnya. Bagi peneliti selanjutnya disarankan untk menggunakan reword sebagai alat atau media yang digunakan untuk meningkatkan durasi ketahanan duduk siswa autis.

\section{Daftar Rujukan}

Damri. (2016). Mengurangi Perilaku Hiperaktivitas Melalui Prosedur Penyisiban Sesaat (Time Out) bagi Anak Autisme”. padang: Universitas Negeri Padang.

Damri, D. (2017). Suppressing the Hyperactivity Behaviour of Students with Autism Through A Time-Out Strategy. International Conference of Early Childhood Education (ICECE 2017). Atlantis Press.

Husni, M. (2018). Analisis Kompreratif dan Sintesa Teori Belajar Konvensional Dengan Teori Belajar Dalam Islam. 05.

Munawaroh, Z. A. (2019). Pengaruh Pemberian Reward Stiker Bintang Terhadap Percaya Diri Anak Kelompok B di TK Thoriqussalam Sidoarjo. Jurnal JECED (Journal of Early Childhood Education and Development), 1(1), 21-29.

Muqoyyaroh, L. (2018). pengaruh reward terhadap kepuasan kerja karyawan PDAM Magetan. EQUILIBRIUM: Jurnal Imiah Ekonomi Dan Pembelajarannya, 6(1), 95101.

Novianti, N. R. (2011). Kontribusi pengelolaan laboratorium dan motivasi belajar siswa terhadap efektivitas proses pembelajaran. Jurnal Pendidikan MIPA. Edisi Khusus, 1, 158-166.

Nurhastuti, mega iswari dan. (2018). pendidikan anak autisme. kuningan: goresan pena.

Pettasolong, N. (2017). Implementasi Budaya Kompetisi Melalui Pemberian Reward And Punishment Dalam Pembelajaran. Tadbir: Jurnal Manajemen Pendidikan Islam, 5(2), 38-52.

Suci Wulandari, I. K. A. (2014). Pengaruh Pemberian Reward and Punishment Terhadap Motivasi Belajar Siswa dalam Pembelajaran Passing Bawah Bolavoli (Studi pada 
Siswa Kelas VIII SMP Negeri 1 Yosowilangun Lumajang). Jurnal Pendidikan Olahraga Dan Kesehatan, 2(3).

Tarmansyah. (2010). Terapi Okupasional. jakarta: Direktorat Pendidikan Luar Biasa. 